\title{
A UNIÃO EUROPÉIA E OS DIREITOS HUMANOS DOS IMIGRANTES EXTRACOMUNITÁRIOS
}

\author{
Jaqueline Lisbôa Gruppelli* \\ Jânia Maria Lopes Saldanha**
}

Como se manter aberto aos negócios e fechado às pessoas? Fácil. Primeiro você amplia o perímetro, depois tranca a porta.

Naomi Klein in Zygmunt Bauman, Vidas Desperdiçadas, 2005, p. 79.

RESUMO: O presente artigo versa sobre as políticas de imigração e integração adotadas na União Européia. Neste sentido, pretende demonstrar em que medida as políticas de imigração ameaçam a manutenção dos direitos humanos dos indivíduos de terceiros países, sejam eles imigrantes legais ou ilegais. O trabalho torna-se importante à medida que se compreendem a existência de obstáculos fronteiriços aos não cidadãos europeus, em função da presença do Estado soberano e a inexistência desses aos nacionais da União. Tal fato corrobora a discrepância existente entre as políticas de integração e proteção dos direitos humanos, asseguradas aos cidadãos comunitários, e as políticas de imigração e descumprimento dos direitos humanos dos cidadãos extracomunitários, cujo intuito seja o de ingressar na União Européia. Sugere-se, portanto, uniformização dos procedimentos nas áreas fronteiriças exteriores ao bloco, de forma que sejam criados modelos de uma política comunitária de imigração e inserção dos imigrantes na Comunidade Européia, alicerçados na proteção dos direitos humanos dos nacionais de terceiros países.

PALAVRAS-CHAVE: Direitos Humanos. União Européia. Imigração. Integração.

ABSTRACT: The present paper deals about the immigration and integration policies adopted in the European Union. Through this, it intends to demonstrate in which way the immigration policies threat the maintenance of human rights of persons from third countries, whoever they may be legal or illegal immigrants. The work becomes important as we understand the existence of borders obstacles to nonEuropean citizens, due to the presence of sovereign State and the inexistence of those to the Union nationals. This fact shows the discrepancy existent among the integration policies and the protection of human rights, assured to European citizens, and the immigration policies and non-accomplished of human rights of the extra communal citizens, whose aspiration is to get in the European Union. It is suggested, therefore, the standardization of proceedings in external borders areas to the block, so that patterns of a communal policy of immigration and insertion of immigrants in European Community can be created, built on the protection of human rights of nationals of third countries.

KEY-WORDS: Human Rights. European Union. Immigration. Integration.

"Mestranda em Integração Latino-Americana na Universidade Federal de Santa Maria/RS (MILA/UFSM). Bolsista da CAPES. E-mail: jaquegruppelli@ hotmail.com. Orientadora: Prof ${ }^{\mathrm{a}} \mathrm{Dr}^{\mathrm{a}}$ Jânia Maria Lopes Saldanha.

Doutora em Direito Público da Unisinos. Coordenadora e Professora do Curso de Mestrado em Integração Latino-Americana na Universidade Federal de Santa Maria/RS (MILA/UFSM). Advogada. E-mail: janiasaldanha@gmail.com. 


\section{INTRODUÇÃO}

Desde os primórdios da criação do mundo, a mobilidade humana tem se caracterizado por fazer parte da vida dos seres humanos. A busca incessante pela sobrevivência, a necessidade de obter melhores condições de vida, a fuga em razão de guerras e perseguições religiosas são fatores que encorajam o homem a deslocar-se pelo mundo, transpor fronteiras, abandonar seu território de origem.

Exemplo histórico de movimentos migratórios dos seres humanos em busca de melhores condições de vida se dá com o término da Segunda Guerra Mundial. Os países devastados pela guerra tiveram grande parte de seus cidadãos migrando para outros territórios, na tentativa de lutar por melhores condições de vida.

A Europa, portanto, devastada pela guerra, necessita reconstruir-se a partir de uma cooperação e integração entre os Estados, visando uma reestruturação econômica bem como social. Há, neste contexto, um anseio incipiente de um mundo de liberdade e direitos dos seres humanos.

A nova fase de união, alicerçada por diversos Tratados, tem, como foco, dentre outros, a reconstrução dos direitos dos seres humanos envolvidos. Neste sentido, a adoção da cidadania comum européia é, sem dúvida, sinônimo de conquista social, de forma que permite aos indivíduos do bloco o livre trânsito na esfera da União. Por outro lado, no que se refere aos indivíduos de terceiros países que queiram ingressar em solos europeus, existem impedimentos e barreiras representados pelas áreas de fronteiras exteriores à União.

Por certo que a estrutura da política adotada e a situação de vida proporcionada pelos países integrantes do bloco europeu são convidativas para que cidadãos extracomunitários, tratando aqui especificamente dos menos favorecidos, sejam eles do Leste Europeu, da África, Oriente Médio, das Américas e etc., sejam impulsionados a ingressar neste bloco, independentemente da maneira adotada.

Situações de extrema pobreza vivenciadas no continente Africano, de constantes guerras e discriminações no Oriente Médio, ou de incertezas políticas de outras regiões, fazem com que os seres humanos percam a noção de leis, a fim de tentarem ingressar em terras que, aparentemente, possam lhes oferecer realidades diversas das que vivem em seus países de origem.

Destarte, o presente trabalho tem como escopo identificar a posição da União Européia em relação aos direitos humanos dos imigrantes extracomunitários e em que medida este bloco regional ameaça a manutenção dos direitos humanos dos indivíduos 
de terceiros países. Encontra-se, portanto, disposto em dois tópicos: o primeiro, abordando o aspecto político da União, ao tratar das políticas de imigração e integração no bloco; já o segundo tópico trata do aspecto social, abordando os direitos humanos dos imigrantes legais e ilegais na esfera da União Européia.

Diante disso, não se pretende excluir a autonomia de segurança interna dos Estados-membros, até porque cada vez mais o mundo presencia situações que abalam as estruturas de segurança mundial. No entanto, pretende-se propor mecanismos uniformes de receptividade e inserção social às pessoas menos favorecidas de terceiros países, sejam elas imigrantes legais ou ilegais.

\section{POLÍTICAS DE IMIGRAÇÃO E INTEGRAÇÃO NA UNIÃO EUROPÉIA}

A partir dos Tratados Constitutivos da União Européia, este bloco não somente criou um mercado comum como, também, adotou diversas medidas que aboliram obstáculos à livre circulação de bens, serviços, capitais e pessoas entre os Estadosmembros.

Especificamente em relação à livre circulação de pessoas, a política de integração da União assume amplas proporções com a adoção de uma cidadania comum aos nacionais de seus países, a qual consagra o direito de ir e vir e de instalar-se livremente dentro do âmbito europeu. Tais direitos encontram-se consagrados no Tratado da União Européia (TUE), cujo teor foi feito na cidade holandesa de Maastricht, em 1992, por isto também chamado de Tratado de Maastricht.

A aplicação do princípio da liberdade de circulação de pessoas amplia-se com a supressão das fronteiras interiores, com fulcro no Acordo Schengen, cujo objetivo é promover uma maior efetivação da livre circulação, com o intuito de diminuir de forma gradual os controles nas fronteiras internas. Firmado na cidade de Schengen (Luxemburgo) em 1985, este Acordo inicialmente possuía a adesão de apenas alguns países da União, possuindo um caráter intergovernamental.

Já em 1990, a convenção de execução de Schengen fixa regras comuns em medidas sobre vistos, circulação de estrangeiros, asilo, cooperação judiciária, polícia e segurança, extradição e intercâmbio de informação. Esta supressão dos controles fronteiriços internos encontra-se apoiada pelo Sistema de Informação de Schengen (SIS), o qual fornece dados acerca da entrada e saída de pessoas de terceiros países, a emissão de vistos e a cooperação policial, instrumento este reservado às autoridades e polícias responsáveis pelos controles nas fronteiras externas. 
No ano de 1997, o Tratado de Amsterdã incorporou o Acordo Schengen no seu marco institucional deixando, portanto, de assumir um caráter intergovernamental. Trata-se de estabelecer progressivamente um espaço sem controle de pessoas nas fronteiras internas, independentemente de sua nacionalidade, criando um espaço de liberdade, segurança e justiça, com métodos mais eficazes e democráticos. Ressalte-se que os Estados-membros da União Européia aderiram a este sistema de cooperação, com exceção do Reino Unido e da Irlanda. ${ }^{1}$

Os documentos citados têm como objetivo principal uma união cada vez mais estreita entre os povos da Europa, de forma que os benefícios em favor dos cidadãos europeus pressupõem um alargamento nas políticas de integração européia, principalmente no âmbito econômico, já que é através dos seres humanos e do pleno exercício de seus direitos que se consagra um bloco forte economicamente.

Da mesma forma, a ausência das fronteiras interiores promove uma maior cooperação e solidariedade, através da aproximação dos povos, intercâmbio de culturas, experiências, enfim, há uma maior integração em benefício dos nacionais comunitários e seus familiares, mesmo estes não possuindo nacionalidade de um Estado da União.

No entanto, as pessoas além fronteiras da União Européia já não possuem o mesmo tratamento em relação aos nacionais do bloco. Os Tratados que instituíram a União tornam-se falhos à medida que são omissos no que concerne à uniformização de uma política de imigração aos indivíduos de terceiros países.

Neste sentido, dispõe o Artigo K.1 do Tratado da União Européia:

Para a realização dos objetivos da União, nomeadamente o da livre circulação de pessoas, e sem prejuízo das atribuições e competências da Comunidade Européia, os Estados-membros consideram questões de interesse comum os seguintes domínios: 1) A política de asilo; 2) As regras aplicáveis à passagem de pessoas nas fronteiras externas dos Estados-membros e ao exercício do controle dessa passagem; 3) A política de imigração e a política em relação aos nacionais de países terceiros; a) As condições de entrada e de circulação dos nacionais de países terceiros no território dos Estados-membros; b) As condições de residência dos nacionais de países terceiros no território dos Estados-membros, incluindo o reagrupamento familiar e o acesso ao emprego; c) A luta contra a imigração, residência e trabalho irregulares de nacionais de países terceiros no território dos Estados-membros; (...)

O artigo citado discorre acerca das questões de interesse comum aos Estadosmembros, mais precisamente à situação da entrada e circulação dos nacionais de

\footnotetext{
${ }^{1}$ Estes países podem participar na totalidade ou em parte das disposições do acervo de Schengen, após votação do Conselho por unanimidade dos treze Estados que tomaram parte nos acordos e do representante do governo do Estado interessado. Já a Islândia e a Noruega, embora não fazerem parte da União Européia, são associadas à aplicação do acervo de Schengen e ao prosseguimento do seu desenvolvimento. Disponível em: $<$ http://europa.eu/scadplus/leg/pt/lvb/133020.htm> Acesso em: 28 ago. 2006.
} 
terceiros países no âmbito do bloco. Entretanto, a política de imigração da União Européia se caracteriza por ser um sistema de cooperação intergovernamental entre os Estados-membros; e não, uma política de caráter supranacional, ou seja, não existem regras comuns aos países da União em relação à imigração de cidadãos extracomunitários. Estes indivíduos ficam condicionados a normas específicas do país no qual desejam ingressar, podendo estas serem completamente diferentes no país vizinho.

É notório que os países da União Européia são afetados diariamente pelo fluxo da migração internacional, sejam migrantes legais ou ilegais. No que tange à imigração legal, a União reconhece que estes indivíduos são importantes em certos setores de trabalho e regiões com o propósito de servirem para as necessidades econômicas e demográficas. Porém, há um déficit de inserção social comunitário para estes indivíduos, com questões relacionadas à xenofobia e ao racismo. No contexto da imigração ilegal, as redes de traficantes tentam levar vantagem sobre as pessoas desesperadas por melhores condições de vida.

Diante disso, partindo do pressuposto de que era necessária uma nova aproximação para administrar a migração, os líderes da União Européia empenharam-se em criar, no ano de 1999 em Tampere (Finlândia), elementos para uma política de imigração comum na União Européia, os quais foram confirmados em 2004 com a adoção do Programa de Haia. Este Programa estabelece objetivos para o fortalecimento da liberdade, segurança e justiça no âmbito europeu, com prioridades para o período de 2005 até $2010 .^{2}$ Não obstante, este plano de reforço tem mecanismos de avaliação e aplicação de forma individual por cada Estado-membro. A soberania estatal controla os movimentos de entrada e saída em suas fronteiras, ditando as regras segundo seus próprios interesses. $^{3}$

Neste diapasão, Habermas ${ }^{4}$ aponta que a soberania do Estado tem como fundamento o reconhecimento da integridade e autonomia das fronteiras territoriais, sendo recíproco o reconhecimento deste direito, tanto internamente como diante dos

\footnotetext{
${ }^{2}$ As dez prioridades postas no Programa de Haia são: reforçar os direitos fundamentais e a cidadania; lutar contra o terrorismo; definir uma abordagem equilibrada sobre a migração, tanto legal como ilegal; instaurar um procedimento comum em matéria de asilo; maximizar o impacto positivo da imigração; desenvolver uma gestão integrada das fronteiras externas da União; encontrar um justo equilíbrio entre o respeito da vida privada e a segurança na partilha de informações; elaborar um conceito estratégico para a criminalidade organizada; garantir um verdadeiro espaço europeu de justiça; e, por fim, partilhar as responsabilidades e assegurar a solidariedade. Disponível em: 〈http://europa.eu/scadplus/leg/pt/lvb/116002.htm> Acesso em: 28 ago. 2006.

${ }^{3}$ Em outubro de 2004, através do Regulamento (CE) n ${ }^{\circ}$ 2007/2004, foi criada uma Agência Européia de Gestão da Cooperação Operacional nas Fronteiras Externas dos Estados-membros da União Européia (FRONTEX) que tem como objetivo melhorar a gestão integrada destas áreas, além de facilitar a aplicação de medidas comunitárias relacionadas à gestão das fronteiras exteriores. Porém, o controle e vigilância das fronteiras externas continuam sendo de responsabilidade dos Estados-membros. A sede da Agência fica em Varsóvia (Polônia), onde assume suas funções desde 01 de maio de 2005. Disponível em: 〈http://europa.eu/scadplus/leg/pt/lvb/133216.htm> Acesso em:13 jul. 2007.

${ }^{4}$ HABERMAS, Jürgen, A constelação pós-nacional: ensaios políticos. São Paulo: Littera Mundi, 2001, p. 82.
} 
demais sujeitos do direito internacional. Além disto, acrescenta que a função protetora do Estado é a de manter a ordem dentro das fronteiras internas, garantindo aos indivíduos segurança no seu mundo da vida privado. Em contrapartida, ressalta o autor, o Estado evoca a vontade política de fechamento das comportas contra a incontrolável "maré" invasora que vem de fora, na tentativa de conter os imigrantes que supostamente põem em perigo a segurança interna. ${ }^{5}$

Percebe-se, pois, que as políticas de imigração na União Européia encontram-se em descompasso com as políticas de integração do bloco. O modelo de integração reservado aos cidadãos europeus estreita a política imigratória européia, visto que a eles são consagrados direitos e proteção de forma uniforme na esfera da União. Por outro lado, aos nacionais de terceiros países são restringidos vários direitos relacionados à liberdade de ingresso e locomoção no bloco europeu, ficando estes a mercê das regras internas impostas por cada Estado-membro. Consagra-se uma Europa fechada, aberta somente àqueles que possuem o direito de livre trânsito e estabelecimento.

Por certo as atitudes de atentados terroristas vivenciadas nos últimos anos em diversas partes do mundo têm imputado às pessoas um sentimento de insegurança, medo e desespero. No entanto, estes sentimentos não devem servir como regra para restringir as políticas de integração e imigração Européia.

De acordo com notícias recentemente publicadas na internet, ${ }^{6}$ em função do grande fluxo de imigrantes ilegais somente no ano de 2006, provenientes da África na Espanha, Malta e Itália, a Comissão da União Européia encontra-se estudando medidas para reforçar a segurança fronteiriça, a fim de manter os imigrantes cada vez mais afastados do território europeu. Uma idéia a ser considerada é a criação de um Comissário da Imigração ou de um Comissário da Imigração e Integração que controle assuntos relacionados com a justiça, a segurança, a liberdade bem como com assuntos sociais.

No entanto, a idéia da adoção de uma política comum relacionada às questões imigratórias e integracionistas dos nacionais de terceiros países encontra-se ainda incipiente na Comunidade Européia, existindo apenas programas e propostas neste sentido sendo, por conseguinte, um desafio a ser compartilhado pelos atuais vinte e sete países membros.

\footnotetext{
5 Ibid., p. 103.

${ }^{6}$ Disponível em: <http://www.acime.gov.pt/modules.php?name=News\&file=article\&sid=1497> Acesso em: 06 set. 2006
} 


\section{A PROTEÇÃO DOS DIREITOS HUMANOS DOS IMIGRANTES EXTRACOMUNITÁRIOS NA UNIÃO EUROPÉIA}

Os Direitos Humanos dos cidadãos da União Européia encontram-se consagrados e assegurados nos Tratados ratificados pelos Estados-membros, cujos teores se encontram no mesmo plano de igualdade que as constituições de cada país envolvido.

Dentre vários direitos consagrados, destaca-se a adoção de uma cidadania comum que permite ao indivíduo comunitário o direito de livre locomoção intrabloco, como se estivesse transitando dentro de seu próprio país. Dessa forma, o cidadão comunitário europeu deixa de ser visto como um estrangeiro para ser tratado efetivamente como se fosse nacional do país no qual se encontra inserido, diferenciando-o dos indivíduos pertencentes às fronteiras externas da União.

Porém, esta situação igualitária e de aproximação dos seres humanos presente na Europa-fortaleza, assim denominada para os imigrantes que nela ambicionam ingressar, tem-se fechado cada vez mais.

Diante de um bloco econômico organizado, é inevitável que seja pouco atrativo buscar melhores condições de vida em solos vizinhos, seja de forma legal ou ilegal. Entretanto, os direitos assegurados intrabloco não são os mesmos além fronteiras exteriores. Assim sendo, existe um contra-senso no que tange às aspirações da União e o que realmente ocorre na prática em relação à política de integração e à manutenção dos direitos humanos dos indivíduos de terceiros países.

A grande maioria dos nacionais de terceiros países não tem assegurado o pleno respeito ao disposto no artigo 13 da Declaração Universal dos Direitos Humanos ${ }^{7}$ (DUDH) no âmbito da União, cujo conteúdo preconiza o direito de locomoção e residência a qualquer pessoa em qualquer país.

As aspirações a uma vida mais digna longe de seu território nacional, na tentativa de fugir de catástrofes naturais, guerras, perseguições religiosas, genocídios, xenofobismo, racismo, discriminação, exclusão social, desemprego e etc., fazem com que, diariamente, milhares de pessoas arrisquem suas vidas para entrar na União Européia. Para estes indivíduos não existem regras ou limites para lutar pela sobrevivência e pôr em prática os direitos assegurados no artigo 13 da DUDH, contudo, muitos deles não chegam vivos ao seu destino.

${ }^{7}$ A Declaração Universal dos Direitos Humanos de 1948 positivou internacionalmente os direitos do homem sendo, portanto, o marco histórico e jurídico a orientar as medidas de defesa e proteção dos direitos humanos nas esferas regional e global. 
Destaca-se, portanto, as situações vivenciadas tanto por imigrantes legais como por imigrantes ilegais. Estes se subdividem nos que tentam o ingresso por vontade própria e naqueles que são vítimas do tráfico de pessoas.

Os imigrantes legais, principalmente tratando-se de trabalhadores que têm menos a oferecer ao mercado laboral, são considerados refugos humanos ${ }^{8}$ da sociedade, úteis ao desenvolvimento da União Européia, já que ela precisa dos mesmos para que tarefas primárias básicas possam ser efetuadas e, assim, contribuir para o avanço da economia da União. Trabalhadores que abandonam seu país em busca de melhores condições de vida buscam, além de um emprego (cujo salário na maioria das vezes é ínfimo), um espaço e convivência pacífica em solos europeus.

A convivência de diversas culturas no mesmo espaço implica tolerância mútua entre os cidadãos europeus e os imigrantes legais. Porém, esta tolerância a diversidades interculturais também tem seus limites, já que estas pessoas sofrem preconceitos dos mais diversos, justamente por serem representantes do lixo útil da sociedade. São os próprios indivíduos comunitários que dificultam a inclusão e a integração sociais dos imigrantes legais no âmbito da União. Tais situações ameaçam diretamente a manutenção dos direitos humanos destes indivíduos, pois os mesmos, apesar de encontrarem-se legalmente inseridos na União, têm seus direitos humanos ameaçados justamente por serem estrangeiros.

Infelizmente a sociedade civil, de um modo geral, carrega sentimentos de superioridade em relação a outras pessoas. Não diferente ocorre na Comunidade Européia, no entanto, é dever e obrigação dos Estados-membros promoverem a paz e a harmonia social entre os povos, inclusive entre os imigrantes legais e os cidadãos comunitários.

A receptividade e solidariedade humanitárias são questões fundamentais as quais devem estar diretamente ligadas à educação, ou seja, é de suma importância que o respeito mútuo aos seres humanos venha da base, desde a formação da personalidade do indivíduo. Para tanto, políticas de integração devem ser adotadas nas escolas, de forma que desde cedo os cidadãos compreendam o verdadeiro sentido do que vem a ser integração social. É preciso que essa conscientização seja absorvida pela população comunitária e repassada às demais pessoas, inclusive na forma de acolher e conviver com os imigrantes legais.

\footnotetext{
${ }^{8}$ BAUMAN, Zygmunt. Vidas desperdiçadas. Rio de Janeiro: Jorge Zahar, 2005, p. 78
} 
Já a situação dos imigrantes ilegais tende a ser um problema que atinge proporções maiores em relação às políticas de imigração e integração da União Européia. O grande fluxo de cidadãos ilegais que tenta ingressar nas fronteiras impermeáveis da União (muitos destes são iludidos pelas máfias que traficam seres humanos) é uma questão que traz cada vez mais restrições à entrada destes no território europeu.

Após os atentados terroristas vivenciados em várias partes do mundo, a segurança nacional tem sido tema de constantes debates entre os Estados, razão pela qual agravou a situação de tentativa de ingresso dos nacionais de terceiros países na Europa. A ocorrência dos ataques terroristas fez com que a Comunidade Européia associasse a figura do imigrante com a insegurança, o medo e o pavor. Bauman ${ }^{9}$ afirma que estes imigrantes exalam o odor do refugo humano de lugares distantes e subdesenvolvidos e representam um "perigo para a segurança" Européia.

Um exemplo bastante atual desta problemática de ingresso nos países europeus tem ocorrido na Espanha. Somente no ano de 2006, cerca de 21 mil imigrantes ilegais, provenientes da África, conseguiram chegar até as Ilhas Canárias, as quais ficam próximas à costa oeste africana. Milhares deles tentam chegar à Europa em embarcações precárias, onde muitos morrem tentando fazer a travessia. O governo espanhol tentou entrar em negociações com os países africanos, com o intuito de tentar conter o problema. Além disto, a Espanha também pediu ajuda à União Européia para que fossem reforçadas as áreas fronteiriças com a presença de policiais. ${ }^{10}$

Não bastasse isso, os cidadãos que conseguem ingressar no solo espanhol na maioria das vezes são capturados e abrigados nos centros de recepção das ilhas que acolhem além da sua capacidade; ou, estas pessoas são mantidas em delegacias até que seja decidido o que fazer com elas. É provável que estes indivíduos sejam deportados ao país de origem em condições insalubres e perigosas, afetando diretamente os direitos fundamentais inerentes a qualquer ser humano.

A Europa passa, portanto, de forma gradual, a se tornar um continentefortaleza, ${ }^{11}$ visto que seleciona de forma arbitrária os indivíduos capazes de permanecer em solos europeus que serão úteis ao desenvolvimento da União.

\footnotetext{
${ }^{9}$ Ob. cit., p. 72.

${ }^{10}$ Disponível em: <http://www.bbc.co.uk/portuguese/noticias/story/2006/09/060904_espanhaimigrantesfn.shtml> Acesso em: 18 set. 2006

11 "Um continente-fortaleza é um bloco de nações que unem seus esforços para obter termos favoráveis de outros países, enquanto patrulham suas fronteiras externas comuns para manter de fora as pessoas desses países. Mas se um continente exerce com seriedade a função de fortaleza, também deve convidar um ou dois países pobres para participar, já que alguém precisa fazer o trabalho sujo e pesado.” Bauman apud Naomi Klein. Ob. cit., p. 78 .
} 
Desta forma, conforme as regras de intergovernamentabilidade impostas pela União Européia, cada país "receptor" dispõe da medida que julga adequada para lidar com a situação de determinado ser humano extracomunitário.

Ante o exemplo ocorrido na Espanha, percebe-se que somente a ação soberana individual de cada país não basta para conter o fluxo de imigrantes ilegais. É preciso uma política uniforme que seja capaz de conciliar o inconciliável, de maneira que as fronteiras assimétricas Européias garantam tanto uma uniformização da política imigratória em suas fronteiras exteriores bem como uma política de integração efetiva dos imigrantes, cuja atuação esteja diretamente ligada à proteção dos direitos humanos destes cidadãos.

\section{CONSIDERAÇÕES FINAIS}

Os constantes movimentos de imigração na União Européia têm ocasionado estreitamento nas fronteiras exteriores ao bloco, o qual vai de encontro à política Comunitária adotada pelos Estados-membros de promoção da paz, solidariedade e cooperação internacional.

Tal fechamento das fronteiras ocorre em virtude das inconstâncias sociais vivenciadas pela humanidade nos últimos anos. Com o intuito de reforçar a segurança interna, a Europa tem dificultado a entrada de indivíduos de terceiros países em sua região.

Com o direito de livre circulação aos cidadãos da União, foi e é possível alavancar o desenvolvimento econômico e social do bloco, visto que há trocas de experiências entre os cidadãos ao deixarem seu país de origem.

Não obstante, com a abertura das fronteiras internas, surgem alguns problemas no que tange às fronteiras exteriores ao bloco. $\mathrm{O}$ primeiro diz respeito à necessidade de harmonização legislativa em relação às formas de controle nestes limites; já o segundo relaciona-se com as condições de entrada e circulação de cidadãos não comunitários na esfera da União e a conseqüente inserção destes na sociedade européia.

Montam-se barreiras além fronteiras exteriores de modo excludente. Há, pois, uma contradição presente no modelo de integração europeu já que, mesmo com objetivos integracionistas, a situação das pessoas de terceiros países que queiram ingressar nessa União-fortaleza fica condicionada às normas institucionais de cada Estado soberano, o qual aplica as leis de acordo com suas necessidades, selecionando a entrada desses indivíduos conforme seus interesses econômicos. 
Esta lacuna que se verifica no direito comunitário europeu em relação à proteção dos direitos humanos dos imigrantes poderá ser preenchida, à medida que certas atitudes políticas dos Estados-membros sejam modificadas, principalmente no que se refere à prerrogativa da soberania nacional.

Diante da realidade apresentada, imprescindível que a União Européia concentre seus esforços no sentido de buscar eqüidade e uniformidade de tratamento destes cidadãos considerados refugos da sociedade cosmopolita, reservando políticas de socialização e integração aos imigrantes legais. Já aos imigrantes ilegais, deve a União criar mecanismos de ajuda humanitária que protejam os direitos básicos e fundamentais dos mesmos, seja nos seus países de origem ou nas áreas das fronteiras exteriores ao bloco.

\section{REFERÊNCIAS BIBLIOGRÁFICAS}

ALMEIDA, Elizabeth Accioly Pinto de. Mercosul \& União Européia: estrutura jurídico-institucional. Curitiba: Juruá, 1996.

BATISTA, Vanessa Oliveira. União Européia: livre circulação de pessoas e direito de asilo. Belo Horizonte: Del Rey, 1997.

BAUMAN, Zygmunt. Vidas desperdiçadas. Rio de Janeiro: Jorge Zahar, 2005.

CAVARZERE, Thelma Thais. Direito internacional da pessoa humana: a circulação internacional de pessoas. 2. ed. rev. e atual. Rio de Janeiro: Renovar, 2001.

HABERMAS, Jürgen, A constelação pós-nacional: ensaios políticos. São Paulo: Littera Mundi, 2001.

LEGISLAÇÃO INTERNACIONAL. Organização Ricardo Seitenfus. Barueri, São Paulo: Manole, 2004.

PFETSCH, Frank R. A União Européia: história, instituições, processos. Brasília: Editora Universidade de Brasília: Imprensa Oficial, 2001.

PORTAL DA BBC BRASIL. Disponível em: <http://www.bbc.co.uk/portuguese/noticias/story/2006/09/060904_espanhaimigrantesfn .shtml> Acesso em: 18 set. 2006.

PORTAL DA UNIÃO EUROPÉIA. Disponível em: <http://europa.eu/scadplus/leg/pt/lvb/133020.htm> Acesso em: 28 ago. 2006.

PORTAL DA UNIÃO EUROPÉIA. Disponível em: $<$ http://europa.eu/scadplus/leg/pt/lvb/116002.htm> Acesso em: 28 ago. 2006.
PORTAL DA UNIÃO $\quad$ EUROPÉIA. <http://europa.eu/scadplus/leg/pt/lvb/133216.htm> Acesso em:13 jul. 2007.

PORTAL DO ALTO COMISSARIADO PARA A IMIGRAÇÃO E MINORIAS ÉTNICAS. Disponível em: $<$ http://www.acime.gov.pt/modules.php?name=News\&file=article\&sid=1497> Acesso em: 06 set. 2006.

VENTURA, Deisy. As assimetrias entre o Mercosul e a União Européia: os desafios de uma associação inter-regional. Barueri, SP: Manole, 2003. 